\title{
Biases of SRTM in high-mountain areas: Implications for the monitoring of glacier volume changes
}

\author{
E. Berthier, ${ }^{1}$ Y. Arnaud, ${ }^{2}$ C. Vincent, ${ }^{3}$ and F. Rémy ${ }^{4}$ \\ Received 6 February 2006; revised 15 March 2006; accepted 21 March 2006; published 25 April 2006.
}

[1] Because of its nearly global coverage, the Shuttle Radar Topographic Mission (SRTM) topography is a promising data set for estimating mountain glacier volume changes. But, first, its absolute accuracy must be thoroughly investigated in a glacial environment. We use topographic data available in the French Alps to assess the usefulness of SRTM for the monitoring of glacier volume variations. We observe clear biases with altitude both on ice-free and glacier-covered areas. At high altitudes, SRTM elevations are underestimated by up to $10 \mathrm{~m}$. These biases can have a significant impact on any estimate of glacier volume changes. If SRTM is the most recent of the two compared topographies, the volume loss is overestimated (and vice versa). We cannot conclude definitively on the origin of these biases and whether they affect all high-mountain areas but our findings invite reconsideration of previous estimates of glacier wastage based on SRTM. Citation: Berthier, E., Y. Arnaud, C. Vincent, and F. Remy (2006), Biases of SRTM in high-mountain areas: Implications for the monitoring of glacier volume changes, Geophys. Res. Lett., 33, L08502, doi:10.1029/ 2006GL025862.

\section{Introduction}

[2] Glacier mass balance, the change in mass of a glacier over a certain time period, is considered a reliable indicator of ongoing climate changes [Intergovernmental Panel on Climate Change (IPCC), 2001]. For instance, series of glacier mass balance have been used to detect a worldwide acceleration of the hydrological cycle [Dyurgerov, 2003] or as evidence of homogeneous warming across the Alps [Vincent et al., 2004]. Mass balance is also the key variable to quantify the contribution of glaciers to present-day sea level rise. Yet, among the estimated 160000 glaciers on Earth, few have been sampled in the field: only 80 to 90 glaciers have been monitored for at least 10 consecutive years and recently, a few long term mass balance monitoring programs have been cancelled for economic reasons in the Former Soviet Union, Europe, North America and Himalaya. Remote sensing has proved to be an effective tool for extending the number of studied glaciers, in particular large

\footnotetext{
${ }^{1}$ Earth and Ocean Sciences, University of British Columbia, Vancouver, British Columbia, Canada.

${ }^{2}$ Institut de Recherche pour le Développement, Great Ice, Laboratoire de Glaciologie Geophysique de l'Environnement, St. Martin d'Hères, France.

${ }^{3}$ Laboratoire de Glaciologie Geophysique de l'Environnement (UJFCNRS), St. Martin d'Hères, France.

${ }^{4}$ Observatoire Midi-Pyrénées, Laboratoire d'Etudes en Géophysique et Océanographie Spatiales, Toulouse, France.
}

Copyright 2006 by the American Geophysical Union. 0094-8276/06/2006GL025862 glaciers located in remote areas [Arendt et al., 2002; Rignot et al., 2003].

[3] A first step toward mass balance measurement from air- or space-borne sensors is an accurate determination of glacier elevation changes. This can be achieved by comparing glacier digital elevation models (DEM) obtained for different years [Berthier et al., 2004]. In this respect, the February (Feb.) 2000 SRTM (Shuttle Radar Topographic Mission) data set, with its large spatial coverage and its 3 arc sec resolution, is promising. For example, SRTM has been combined with older aerial DEMs to assess the contribution of the Patagonian icefields to global sea level rise [Rignot et al., 2003] or confirm the wastage of Alaskan glaciers [Muskett et al., 2003]. More recently, the comparison with ICESat elevation profiles has revealed thickness changes on the Malaspina Glacier [Sauber et al., 2005].

[4] Yet, although the accuracy of SRTM has been widely investigated on most of the Earth surfaces [e.g., Carabajal and Harding, 2006], a thorough examination of its precision in glacial environment is still to be performed. Such a study is important because SRTM is now widely used to assess ongoing glacier changes. We address this issue by comparing SRTM elevations with topographic data available in the Mont Blanc area (French Alps). After presenting the different data sets, we assess the accuracy of SRTM on the rugged topography surrounding the glaciers and then on the glaciers themselves. Eventually, we discuss the implications of our findings on glacier volume changes derived from SRTM data.

\section{Data}

\subsection{SRTM}

[5] The SRTM mission was flown in Feb. 2000 and provides a topography covering continental areas from $60^{\circ} \mathrm{N}$ to $56^{\circ} \mathrm{S}$ [Rabus et al., 2003] with a 1 and 3 arc sec spatial resolution (about 30 and $90 \mathrm{~m}$ ). The 1 arc sec data set is publicly available for the United States (US, including Alaska) only and, thus, not considered here. Over nonglacierized areas, the initial mission specifications in terms of vertical accuracy ( $\pm 16 \mathrm{~m}$ linear error at the $90 \%$ confidence level) are fulfilled [Sun et al., 2003]. For instance, by comparing SRTM (1 arc sec) with ICESat for the western US, Carabajal and Harding [2005] found a mean and standard deviation of elevation differences of $-0.60 \pm$ $3.46 \mathrm{~m}$ over area with low relief and $-5.61 \pm 15.68 \mathrm{~m}$ for higher relief. For the 3 arc sec data set, the standard deviations are even greater $(>30 \mathrm{~m})$ for the rugged relief of Central Asia where no bias is observed [Carabajal and Harding, 2006].

[6] Only a few studies considered SRTM in a glacial environment. For the Gruben area (Swiss Alps), Kääb 
[2005] found a standard deviation of $\pm 20 \mathrm{~m}$ for SRTM ( 3 arc sec). This study does not determine a bias for the 3 arc sec data set but indicates that the 1 arc sec DEM is, on average, $7 \mathrm{~m}$ too high.

[7] The SRTM DEM for the Mont Blanc area $\left(7^{\circ} \mathrm{E}\right.$, $46^{\circ} \mathrm{N}$ ) was downloaded at ftp://e0srp01u.ecs.nasa.gov (Figure S1). ${ }^{1}$ As in other high-mountain regions, the DEM presents data voids due to the acquisition geometry of SAR images.

\subsection{IGN and SPOT5 DEMs}

[8] Two DEMs of the Mont Blanc area are used to assess the accuracy of SRTM. A DEM has been computed from a stereoscopic pair of SPOT5 images acquired on 19 and 23 August 2003 [Berthier et al., 2004]. The low gain of satellite images insures a good radiometric contrast on the highly reflective snow-covered accumulation zone of glaciers. The resolution is $20 \mathrm{~m}$. On the Mer de Glace and Argentière glaciers, SPOT5 elevations have been systematically compared to differential GPS surveys performed between 1800 and $2700 \mathrm{~m}$, one week before the acquisition of the satellite images. SPOT5 elevations are $0.15 \pm 1.1 \mathrm{~m}$ $(\mathrm{N}=29)$ higher than the ground surveys, indicating the high accuracy of this DEM. A DEM was also obtained from the French National Geographic Institute (IGN) which derived surface elevations from aerial photographs acquired in (or close to) 1979. The resolution is $80 \mathrm{~m}$ and the coverage restricted to the French side of the mountain range. The difference with SPOT5 elevations shows no bias in the IGN DEM but a large standard deviation $(21 \mathrm{~m})$.

\subsection{Topographic Surveys}

[9] Topographic transverse surveys are performed each year in September on Mont Blanc glaciers by LGGE (Figure S1). Five profiles are measured on the Mer de Glace and four on the Argentière glacier in the ablation zone, at altitudes ranging from 1550 to $2700 \mathrm{~m}$ (the ELA is around $2800 \mathrm{~m}$ ). The typical accuracy of each profile is $\pm 0.3 \mathrm{~m}$. These data are available at http://www-lgge.obs.ujfgrenoble.fr/ServiceObs/.

[10] Prior to comparison, all data are converted to a common UTM projection (zone 32N, WGS-84 reference system).

\section{Accuracy of SRTM off the Glaciers}

[11] We first compare the different DEMs on the ice-free area below $3100 \mathrm{~m}$. At higher elevations (Mont Blanc reaches $4810 \mathrm{~m}$ ), only sparse, small and steep rock outcrops are present so comparing the DEMs is useless. The three topographies are subtracted pair-wise and the mean, standard deviation computed (Table 1). Additionally, the mean difference is estimated for each altitude range, then plotted as a function of altitude and, finally, a linear trend is fitted to detect any bias with altitude (Alt. bias in Table 1 and Figure S2).

[12] The mean differences between the three DEMs are small, the standard deviations about 15 to $20 \mathrm{~m}$, which is expected for a rugged topography [Kääb, 2005]. The most striking feature of this comparison is the strong biases (about

\footnotetext{
${ }^{1}$ Auxiliary material is available at $\mathrm{ftp}: / / \mathrm{ftp}$. agu.org/apend/gl/ $2006 \mathrm{gl025862.}$
}

Table 1. Comparison of the Three Different DEMs on the Ice-Free Area $^{\mathrm{a}}$

\begin{tabular}{llccc}
\hline & Mean & Stdev. & Alt. Bias & \multicolumn{1}{c}{$\mathrm{N}$} \\
\hline SPOT5-IGN & 0.5 & 21.2 & +2.3 & 87466 \\
SRTM-IGN & -2.5 & 21.7 & -7.8 & 233507 \\
SRTM-SPOT5 & 0.44 & 15.7 & -7.0 & 204518 \\
\hline
\end{tabular}

${ }^{\mathrm{a}}$ The mean difference (noted Mean, in $\mathrm{m}$ ), standard deviation (Stdev., in $\mathrm{m}$ ) and the bias as a function of altitude (Alt. bias, in m every $1000 \mathrm{~m}$ ) are given. The last column $(\mathrm{N})$ indicates the number of pixels used to compute the statistics.

$-7 \mathrm{~m}$ every $1000 \mathrm{~m}$ ) in SRTM as a function of altitude: SRTM elevations tend to be overestimated below 1700-1800 m and underestimated at higher altitudes. The hypothesis of biases of similar magnitude in both the IGN and SPOT5 DEMs is unlikely because the two data sets are totally independent. Furthermore, no such bias has been observed when comparing the SPOT5 DEM with 29 precise DGPS measurements (the "Alt. bias" is limited to $0.2 \mathrm{~m} / 1000 \mathrm{~m}$ ). These biases are not restricted to the Mont Blanc area. We have observed similar errors $(-9 \mathrm{~m} / 1000 \mathrm{~m}$ between 1700 and $3200 \mathrm{~m})$ in the South French Alps $\left(6.6^{\circ} \mathrm{E}, 44.4^{\circ} \mathrm{N}\right)$ by comparing SRTM and another IGN DEM. Biases of $-8.2 \mathrm{~m} / 1000 \mathrm{~m}$ between 3800 and $5700 \mathrm{~m}$ were also measured in Himalaya $\left(77.5^{\circ} \mathrm{E}\right.$, $32.3^{\circ} \mathrm{N}$ ) by comparing SRTM and SPOT5 DEM [Berthier, 2005]. Previously, Falorni et al. [2005, Figures 3d and 7d] detected errors of the same magnitude for two study sites in the United States but attributed them to their reference data set, not to SRTM. We do not have any definitive explanation to these biases in SRTM data which may originate from one of the numerous processing steps [Rabus et al., 2003]. The underestimation of sharp mountain top elevations and overestimation of narrow valley elevations reported by Rodriguez et al. [2005, Figure 6.7] certainly contribute to these biases in our rugged study area.

\section{Accuracy of SRTM on the Glaciers}

\subsection{Comparison of SRTM With Topographic Profiles}

[13] SRTM data have been acquired in Feb. 2000 which corresponds to mid-winter for the Northern hemisphere when glaciers are covered with snow. As SRTM is derived from C-Band $(\lambda=5.6 \mathrm{~cm})$ SAR data, the penetration of the radar signal in the snow and ice may influence the retrieved elevations. Papa et al. [2002] find a penetration depth $\left(\delta_{p}\right)$ of $1 \mathrm{~m}$ for the snow of the boreal plains. Rignot et al. [2001] measure $\delta_{p}$ of 0 to $4 \mathrm{~m}$ for Alaskan glaciers (increasing with elevation) and up to $10 \mathrm{~m}$ on the dry, cold firn of Greenland ice sheet.

[14] We compare here SRTM elevations with 9 topographic profiles of Mer de Glace and Argentière glaciers located in the ablation zone (Figure S1). For each profile, SRTM elevations are extracted by bicubic interpolation and compared to the field data (Figure 1). SRTM is $2.7 \pm 3.5 \mathrm{~m}$ $(N=9)$ higher than the 2000 profiles. The strong differences at low elevations are due to melting of snow and ice between February and September 2000 that leads to surface lowering of up to $6 \mathrm{~m}$ close to the glacier fronts.

[15] Overall, SRTM elevations are close to the 1999 profiles (difference of $-0.1 \pm 2.1 \mathrm{~m}, N=9$ ) but in detail, a trend appears with altitude, SRTM being about $2 \mathrm{~m}$ too high at low elevation. Part of these differences may originate from real glacier elevation changes between early 


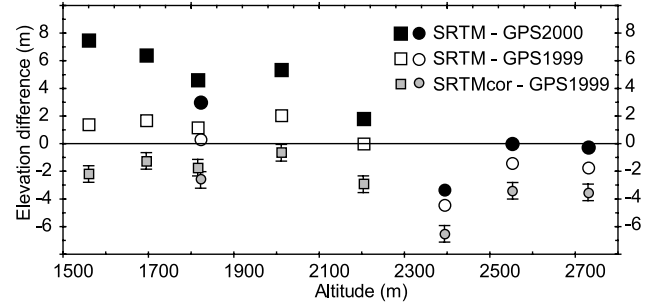

Figure 1. Elevation differences between SRTM and 9 topographic surveys performed on Mer de Glace (squares) and Argentière (circles) glaciers in September 1999 (white symbols) and September 2000 (black symbols). The corrected SRTM elevations (noted SRTMcor) are also compared to the September 1999 survey in grey (see text and Table S1 for more details about these corrected elevations).

September 1999 and mid-February 2000. Using ground data, we correct SRTM profiles by estimating elevation differences induced by: (1) Autumn ablation. Up to $1.4 \mathrm{~m}$ of ablation occurred between the survey of the profiles (10 September 1999) and the end of the ablation season in late October 1999; (2) Glacier flow. Emergent glacier velocities in the ablation zone contribute to glacier thickening (up to $4 \mathrm{~m}$ in 5 months close to the glacier front); (3) Autumn and winter accumulation. A detailed description of these corrections and their uncertainties $( \pm 0.6 \mathrm{~m})$ is provided in Table $\mathrm{S} 1$.

[16] Corrected SRTM elevations are $2.8 \mathrm{~m}$ lower than the September 1999 topographic surveys and the trend with altitude remains. For the 4 profiles above $2200 \mathrm{~m}$, SRTM elevations are underestimated by $4.1 \pm 1.6 \mathrm{~m}$. We identify two possible explanations but cannot conclude here on their relative contribution: (1) Heterogeneous radar penetration. During the days preceding the SRTM mission (11 to $21 \mathrm{Feb}$.), the $0^{\circ} \mathrm{C}$ isotherm, computed from nearby Chamonix temperatures, has reached altitudes up to $1800 \mathrm{~m}$. Thus, the snow below $1800 \mathrm{~m}$ is not dry enough to be transparent to the SRTM radar signal. At higher elevation, the penetration of the C-Band radar signal will be enhanced due to stronger winter accumulation (Table S1) and lower snowpack temperature [Papa et al., 2002]; (2) Instrumental biases. The SRTM biases previously described in the ice-free area have an effect on glacier area.

[17] Despite these biases, one important conclusion is that SRTM maps, in the ablation zone of glacier in the Alps, a surface which is close to the one at the end of the preceding ablation season (September 1999).

\subsection{Comparison of SRTM With Other Glacier DEMs}

[18] The three DEMs are now analysed on the Mer de Glace. When the IGN (1979) and SPOT5 (2003) DEMs are compared, we observe a strong thinning on the lower part of the glaciers and no significant elevation changes in the accumulation zone (Figure 2). When considering separately two periods (by including SRTM data), the thinning at low elevations is still present. However, above $2900 \mathrm{~m}$, the data suggests a 5 to $10 \mathrm{~m}$ thinning between 1979 and Feb. 2000 and a thickening of the same magnitude between Feb. 2000 and 2003.

[19] This observation can be generalized to other glaciers in the Mont Blanc area (Figure 3), suggesting a recent shift from thinning to thickening at high elevations. If real, this

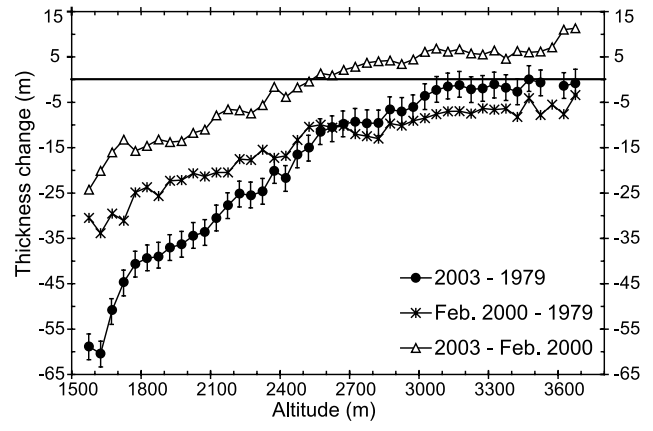

Figure 2. Thickness changes as a function of altitude on the Mer de Glace derived from IGN (1979), SRTM (Feb. 2000) and SPOT5 (2003) DEMs. For the 1979-2003 elevation changes, the errors bars correspond to $\pm 3 \mathrm{~m}$, a conservative value compared to the 1-2 $\mathrm{m}$ obtained previously [Berthier et al., 2004].

signal may be climatically interpreted in terms of increased accumulation. However, this evolution is not supported by any meteorological observations. A recent study has found an increase in temperature and no real trend in precipitation for the period 1958-2002 in the French Alps [MétéoFrance, 2005]. Considering the consistency between IGN and SPOT5 DEMs, it is most likely that this shift is, in fact, an artifact due to errors in SRTM. This assertion is also supported by the biases detected on the ice-free area where SRTM elevations were proved to be underestimated at high elevations. The penetration of the shuttle C-Band radar signal in the cold snow/firn (above about $1800 \mathrm{~m}$ in February) could also contribute (up to $4 \mathrm{~m}$ according to Rignot et al. [2001]) to this underestimation of the glacier elevations.

\section{Implications for the Measurement of Glacier Volume Changes}

[20] The impact of SRTM errors in the determination of glacier volume changes depends on whether SRTM is the most recent or the oldest of the two compared topographies. As observed in the French Alps, we consider here that SRTM elevations are slightly too high in the lower parts of glaciers and too low in their accumulation zone. For a glacier losing mass, the volume loss is overestimated if
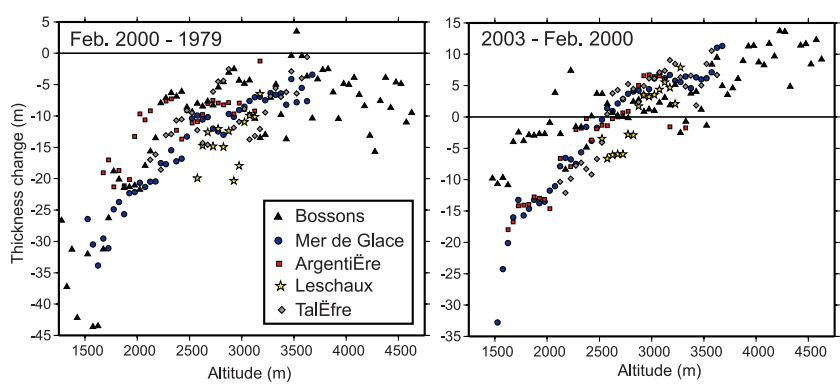

Figure 3. Thickness changes as a function of altitude for 5 glaciers in the Mont Blanc area for (left) 1979-Feb. 2000 and (right) Feb. 2000-2003. The differences in thickness changes between the glaciers is mostly due to their varying aspect and geometry. 


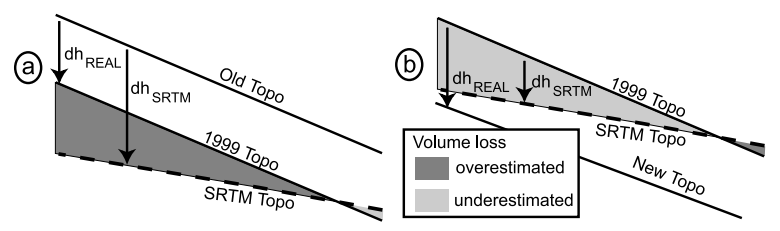

Figure 4. Effect of SRTM biases on volume change estimates. We consider here the case of a glacier experiencing a constant thinning at all altitudes. "Old Topo" (respectively "New Topo") designs a topography older (respectively newer) than SRTM (assumed to map the September 1999 surface).

SRTM is the most recent topography; if SRTM is the oldest topography, the volume loss is underestimated (Figure 4).

[21] We illustrate here how these biases can lead to erroneous mass balance for the Mer de Glace. We assume here a constant densification profile in the accumulation zone and no change in glacier areal extent. Elevation changes obtained by comparing SRTM and SPOT5 DEMs are converted in mass changes using a density of $900 \mathrm{~kg} \mathrm{~m}^{-3}$. We find a mean specific mass balance of $+0.44 \mathrm{~m} \mathrm{a}^{-1}$ (water equivalent). This value is unrealistic because glaciers in the French Alps are known to have experienced a negative cumulative mass balance between 1999 and 2003 [Vincent et al., 2004]. For comparison, the mean mass balance between 1979 and 2003 is $-0.4 \pm$ $0.1 \mathrm{~m} \mathrm{a}^{-1}$ [Berthier, 2005].

[22] We think that the biases in SRTM data, detected here for the French Alps, are not specific to this mountain range. We also observed a suspect thickening of 5 to $10 \mathrm{~m}$ in the upper accumulation zone of the Chhota and Bara Shigri glaciers (Himalaya, India) by subtracting SRTM elevations from a 2004 SPOT5 topography [Berthier, 2005, p. 137]. The strong thinning (4 to $5 \mathrm{~m} / \mathrm{a}$ ) reported between 1995 and 2000 at the equilibrium line of glaciers on the South Patagonian Icefield [Rignot et al., 2003] may also be partly explained by similar SRTM biases.

\section{Conclusion}

[23] In the high-mountain areas of the French Alps, we have detected significant altitudinal biases $(-7 \mathrm{~m}$ every $1000 \mathrm{~m}$ ) in SRTM on the ice free area. SRTM is slightly higher than our reference data at low elevations (below $2000 \mathrm{~m}$ ) and lower by up to $10 \mathrm{~m}$ at higher elevations. For the studied glaciers, these biases can lead to significant errors if SRTM is used to determine glacier volume changes. The magnitude of mass balance errors will be different for each glacier depending on its hypsometry. Similar biases seem to exist in Himalaya suggesting that our observations are not restricted to the Alps. They may also explain (part of) the recent thickness changes observed for glaciers in Alaska and Patagonia. However, we cannot conclude definitively here whether all high-mountain areas are affected until the cause of the bias is clearly identified.

[24] Before using SRTM for monitoring glacier volume changes, a thorough comparison with other topographic data off and on glaciers is recommended. When three DEMs are available, a pair-wise comparison can help detect SRTM biases. Quantifying these biases may then allow their modeling, leading to improved glacier volume changes.

[25] In the French Alps, ground data (topographic surveys) were only restricted to the ablation zone of glaciers. Future similar work based on topographic data acquired in the accumulation zone at the same time (or close to) the SRTM mission would be useful.

[26] The aim of this study was to detect and quantify the biases in SRTM data and their impact in glacier volume change measurements. It is beyond the scope of this article to identify the origin of these biases. On glaciers, penetration of the C-band radar signal in the dry winter snow exists but contribute only up to 3-4 m [Rignot et al., 2001]. The processing of the SAR data is among the causes to be considered in future works.

[27] Acknowledgments. The comments of James E. Saiers (scientific editor) and two reviewers led to significant improvements of the manuscript. We thank Garry Clarke for careful reading on the manuscript. SPOT5 images were acquired thanks to the ISIS program (copyright CNES). All field data are available from the GLACIOCLIM webpage (http://wwwlgge.obs.ujf-grenoble.fr/ServiceObs/). This work was supported by the French national program ACI-OT Glaciers. EB acknowledges a Marie Curie O.I. Fellowship from the EU.

\section{References}

Arendt, A. A., K. A. Echelmeyer, W. D. Harrison, C. S. Lingle, and V. B. Valentine (2002), Rapid wastage of Alaska glaciers and their contribution to rising sea level, Science, 297, 382-386, doi:10.1126/science.1072497.

Berthier, E. (2005), Dynamique et bilan de masse des glaciers de montagne (Alpes, Islande, Himalaya): Contribution de l'imagerie satellitaire (in French), Ph.D. thesis, Univ. Paul Sabatier, Toulouse, France. (Available at http://etienne.berthier.free.fr/download/Berthier_these_2005.pdf.)

Berthier, E., Y. Arnaud, D. Baratoux, C. Vincent, and F. Rémy (2004), Recent rapid thinning of the "Mer de Glace" glacier derived from satellite optical images, Geophys. Res. Lett., 31, L17401, doi:10.1029/ 2004GL020706.

Carabajal, C. C., and D. J. Harding (2005), ICESat validation of SRTM C-band digital elevation models, Geophys. Res. Lett., 32, L22S01, doi:10.1029/2005GL023957.

Carabajal, C. C., and D. J. Harding (2006), SRTM C-band and ICESat laser altimetry elevation comparisons as a function of tree cover and relief, Photogramm. Eng. Remote Sens., 72(3), 287-298.

Dyurgerov, M. B. (2003), Mountain and subpolar glaciers show an increase in sensitivity to climate warming and intensification of the water cycle, J. Hydrol., 282, 164-176.

Falorni, G., V. Teles, E. R. Vivoni, R. L. Bras, and K. S. Amaratunga (2005), Analysis and characterization of the vertical accuracy of digital elevation models from the Shuttle Radar Topography Mission, J. Geophys. Res., 110, F02005, doi:10.1029/2003JF000113.

Intergovernmental Panel on Climate Change (IPCC) (2001), Climate Change 2001: The Scientific Basis: Contribution of Working Group I to the Third Assessment Report of the Intergovernmental Panel on Climate Change, edited by J. T. Houghton et al., 881 pp., Cambridge Univ. Press, New York.

Kääb, A. (2005), Combination of SRTM3 and repeat ASTER data for deriving alpine glacier flow velocities in the Bhutan Himalaya, Remote Sens. Environ., 94, 463-474.

Météo-France (2005), Une étude climatologique des alpes apporte un nouveau signe du réchauffement du climat (in French), Toulouse, France. (Available at http://www.meteofrance.com/FR/actus/dossier/article.jsp? docid $=11700$.)

Muskett, R. R., C. S. Lingle, W. V. Tangborn, and B. T. Rabus (2003), Multi-decadal elevation changes on Bagley Ice Valley and Malaspina Glacier, Alaska, Geophys. Res. Lett., 30(16), 1857, doi:10.1029/ 2003GL017707.

Papa, F., B. Legrésy, N. M. Mognard, E. G. Josberger, and F. Rémy (2002), Estimating terrestrial snow depth with the TOPEX-Poseidon altimeter and radiometer, IEEE Trans. Geosci. Remote Sens., 40, 2162-2169.

Rabus, B., M. Eineder, A. Roth, and R. Bamler (2003), The shuttle radar topography mission-A new class of digital elevation models acquired by spaceborne radar, ISPRS J. Photogramm. Remote Sens., 57, 241-262.

Rignot, E., K. Echelmeyer, and W. Krabill (2001), Penetration depth of interferometric synthetic-aperture radar signals in snow and ice, Geophys. Res. Lett., 28, 3501-3504. 
Rignot, E., A. Rivera, and G. Casassa (2003), Contribution of the Patagonia icefields of South America to sea level rise, Science, 302, 434-437, doi:10.1126/science. 1087393 .

Rodriguez, E., C. S. Morris, J. E. Belz, E. C. Chapin, J. M. Martin, W. Daffer, and S. Hensley (2005), An assessment of the SRTM topographic products, Tech. Rep. JPL D-31639, Jet Propul. Lab., Pasadena, Calif.

Sauber, J., B. Molnia, C. Carabajal, S. Luthcke, and R. Muskett (2005), Ice elevations and surface change on the Malaspina Glacier, Alaska, Geophys. Res. Lett., 32, L23S01, doi:10.1029/2005GL023943.

Sun, G., K. J. Ranson, V. I. Kharuk, and K. Kovacs (2003), Validation of surface height from shuttle radar topography mission using shuttle laser altimeter, Remote Sens. Environ., 88, 401-411.

Vincent, C., G. Kappenberger, F. Valla, A. Bauder, M. Funk, and E. Le Meur (2004), Ice ablation as evidence of climate change in the Alps over the 20th century, J. Geophys. Res., 109, D10104, doi:10.1029/ 2003JD003857.

Y. Arnaud, Institut de Recherche pour le Développement, Great Ice, Laboratoire de Glaciologie Geophysique de 1'Environnement, F-38410 St. Martin d'Hères, France.

E. Berthier, Earth and Ocean Sciences, University of British Columbia, 6339 Stores Road, Vancouver, BC, Canada V6T 1Z4. (etienne.berthier@ cnes.fr)

F. Rémy, Observatoire Midi-Pyrénées, Laboratoire d'Etudes en Geóphysique et Océanographie Spatiales, F-31401 Toulouse, France.

C. Vincent, Laboratoire de Glaciologie Geophysique de l'Environnement (UJF-CNRS), F-38410 St. Martin d'Hères, France. 